\title{
COMPARATIVE STUDY OF SOME BIOACTIVE COMPOUNDS AND THEIR ANTIOXIDANT ACTIVITY OF SOME BERRY TYPES
}

\author{
Amina Aly, Rabab Maraei, Omneya Abou El-Leel
}

\begin{abstract}
Berries are wealthy in bioactive compounds like phenolic compounds and flavonoids that are deemed antioxidants and are great important to health. This research was performed to examine, recognize and compare bioactive compounds in certain types of berries and their antioxidant activity. The data show that blue berry, black berry and Egyptian black mulberry contain the highest content of most bioactive compounds such as phenolic compounds, flavonoids and tannins, while long mulberry and red currant berry have the lowest content for most of these compounds. They therefore, contain the highest value of antioxidant activity. The chemical composition of the berries varies depending on cultivar, variety, location of growth, environmental conditions and harvest time, as well as post-harvest treatments therefore the composition differed from berry fruit to another. Thus, berry fruits are very useful in nutrition to protect the body from many diseases because of its containment of these compounds, which act as free radicals scavenger that harm the body and thus rid the body of many harmful toxins.
\end{abstract}

Keywords: berries; bioactive compounds; phenolic compounds; antioxidant activity

\section{INTRODUCTION}

Berries and small soft-fleshed colored fruits are consumed worldwide for their numerous health benefits. Mature fresh berry fruits contains a large amounts of phytochemical components; phenolic compounds, flavonoids, tannins, carotenoids and anthocyanins (Skrovankova et al., 2015). These compounds used as functional food ingredients in the food industry (Starast et al., 2007). In addition, fruits comprise flavonols and anthocyanins, discovered in big quantities, particularly in dark berries like black currant and bilberry (Govindaraghavan, 2014). Some phenolic acids like $P$-coumaric acid and lignin related to ferulic acid or other cell wall elements can be discovered in berries fruits (Andreasen et al., 2001). Many bioactive compounds are powerful antioxidants, acting as reactive oxygen inhibitors and free radical scavengers and display as antiinflammatory, antiallergic, antihypertensive, anticarcinogenic, antifungal, and antiviral agents (Oszmianski and Lachowicz, 2016). The content of phenolic compounds, flavonoids and anthocyanins can be used to describe the antioxidant activity and thus the potential health benefits of berries fruit (Anttonen and Karjalainen, 2005). Also, berry fruits contains a high content of sugars, diatery fiber and organic acids (oxalic, malic, citric, tartaric and fumaric acids) while, it contains a low content of calorie and fat (Nile and Park, 2014). Berries are a wealthy source of vitamins like Vit. C and folic acid, so the most significant antioxidants in berry fruits are phenolic compounds and ascorbic acid (Beekwilder et al., 2005) influencing dietary importance, sensory characteristics and fruits quality (Lachowicz et al., 2017). The chemical structure of berries is affected by many factors, including variety, environmental factors, maturity stage, harvest time and method, storage conditions and duration (Bobinaitė et al., 2012). In latest years, interest in berries fruits has risen as an element of a good diet due to the elevated quantity of bioactive compounds.

\section{Scientific hypothesis}

Berry fruits contain a number of active compounds responsible for many biological activities that can be used to help protect against many diseases such as cardiovascular disease, cancer and diabetes. This research aims to investigate, identify and compare bioactive compounds (phenolic compounds, flavonoids and tannins) and their antioxidant activity in certain types of berries.

\section{MATERIAL AND METHODOLOGY}

\section{Berry fruits}

Eight types of berry fruits were inclusive in this study: crane berry (Vaccinium macrocarpon), long mulberry (Morus nigra), red currant berry (Ribes rubrum), Egyptian black mulberry (Morus nigra L.), raspberry (Rubus idaeus), black berry (Rubus fructicosus), blue berry (Vaccinium corymbosum) and strawberry (Fragaria 
ananassa). Fruit samples were bought from Cairo-Egypt local market (Figure 1).

\section{Chemicals}

The chemicals and solvents used for this study were of analytical grade and purchased from Merck (Darmstadt, Germany).

\section{Preparation of extracts}

Under liquid nitrogen, fresh samples were homogenized and then lyophilized for 48 hours (Virtis model 10-324). Powder samples were extracted three times at room

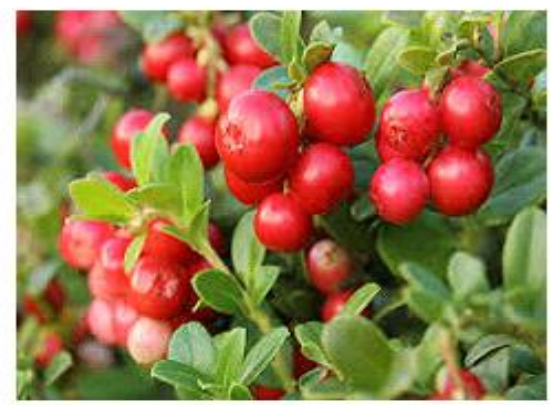

Crane berry

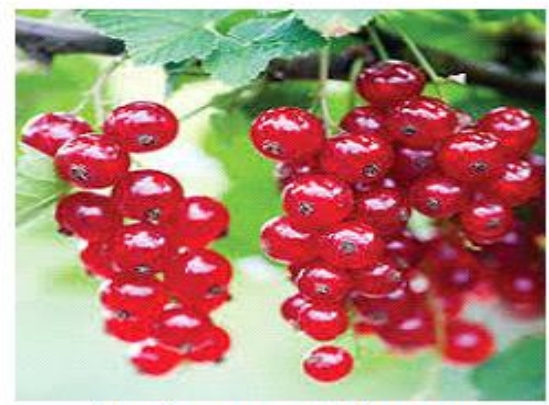

Red currant berry

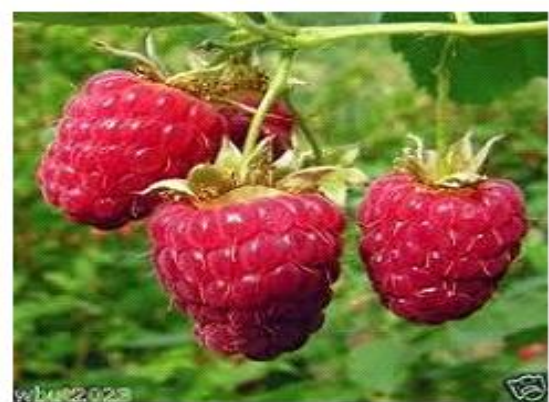

Raspberry

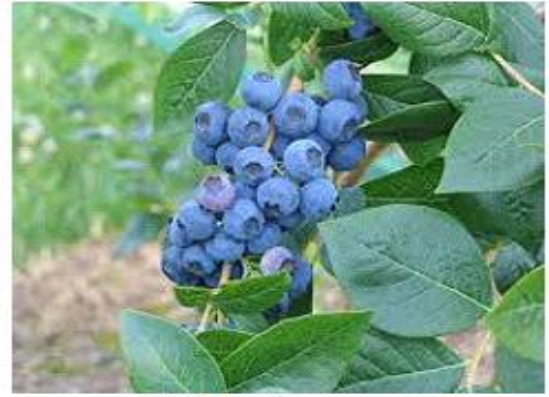

Blue berry temperature using 80 percent ethanol for $24 \mathrm{~h}$. Use rotary evaporator at $40{ }^{\circ} \mathrm{C}$ after filtration and solvent evaporation (Aly et al., 2019). To determine the yield extract, the extracts obtained were weighed. These components have been dissolved in 80 percent ethanol and used for chemical analyses.

\section{Phenolic content}

Phenolic content was analyzed using the Folin-Denis reagent in accordance with Shahidi and Naczk (1995) technique. A one $\mathrm{ml}$ of sample extract was mixed with $0.5 \mathrm{~mL}$ of Folin-Denis and $1.0 \mathrm{~mL}$ of concentrated $\mathrm{Na}_{2} \mathrm{CO}_{3}$ solution, adding $3.0 \mathrm{~mL}$ of distilled water.

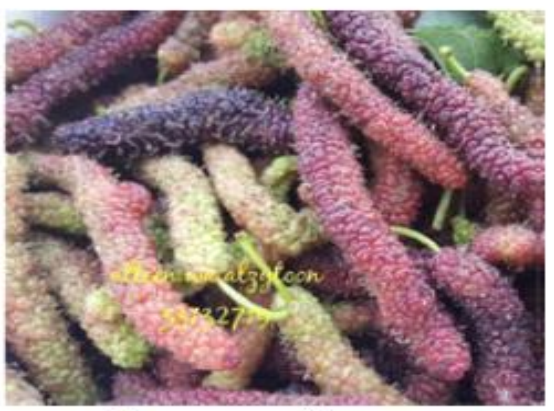

Long mulberry
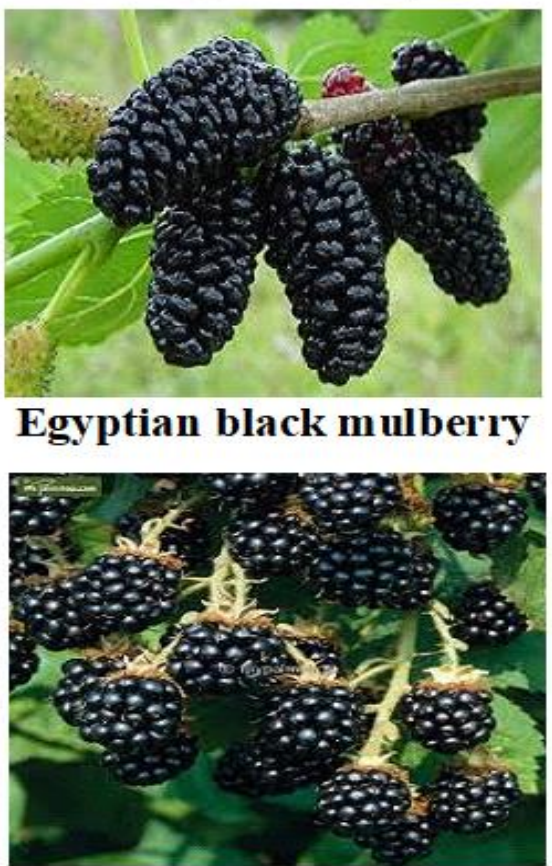

Black berry

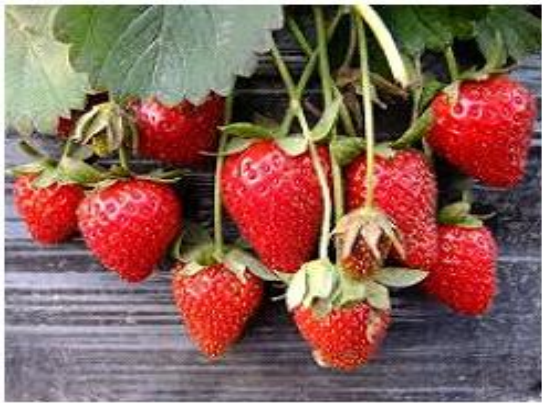

Strawberry

Figure 1 Photograph showing types of some ripe berry fruits used in this study. 
The absorbance was evaluated at $725 \mathrm{~nm}$ against the blank after an hour. The results were expressed as $\mathrm{mg}$ of gallic (GAE) equivalent /g dry weight of extract.

\section{Flavonoids content}

Flavonoids content were determined in the extracts by the aluminum chloride colorimetric assay methods by Marinova et al. (2005). Each ethanolic extract $(1.0 \mathrm{~mL})$ or conventional quercetrin solution has been added to $4.0 \mathrm{~mL}$ distilled water and $0.3 \mathrm{~mL}$ of $5 \% \mathrm{NaNO}_{2}$ has been introduced. Added $0.3 \mathrm{~mL}$ of $10 \% \mathrm{AlCl}_{3}$ after $5 \mathrm{~min}$ and added $2.0 \mathrm{~mL}$ of $1 \mathrm{M} \mathrm{NaOH}$ after $6 \mathrm{~min}$. The absorbance was evaluated at $510 \mathrm{~nm}$ against the blank. Total flavonoids were presented as $\mathrm{mg}$ quercetin (QE) equivalent /g DW of extract.

\section{Tannins content}

The content of tannins was according to a modified vanillin assay (Price et al., 1978) determined the quantity of tannins. One $\mathrm{ml}$ of extract was mixed with $5 \mathrm{~mL}$ of vanillin/ $\mathrm{HCl}$ reagent $(0.5 \mathrm{~g}$ vanillin in methanol $4 \%$ hydrochloric acid (v/v). Samples and control (without vanillin) were permitted to remain for $20 \mathrm{~min}$ in the dark and then the absorbance at $500 \mathrm{~nm}$ was read. Total tannin content was displayed as mg tannic acid equivalent /g DW of extract.

\section{Flavonols content}

Yermakov et al. (1987) determined flavonols. Added one $\mathrm{ml}$ of the sample, $2 \mathrm{~mL}\left(20 \mathrm{~g} . \mathrm{L}^{-1}\right)$ of aluminum trichloride and $3 \mathrm{~mL}\left(50 \mathrm{~g} . \mathrm{L}^{-1}\right)$ sodium acetate solutions. After $2.5 \mathrm{~h}$ at $20^{\circ} \mathrm{C}$ at $440 \mathrm{~nm}$ the absorbance was read by spectrophotometer (Jasco V-530, Japan). The flavonol content was displayed as $\mathrm{mg}$ quercetin equivalent /g dry weight of extract.

\section{Antioxidant activity by: Scavenging activity on DPPH radical}

The radical scavenging activity of extracts against 2,2-Diphenyl-1-picryl hydrazyl (DPPH) radical was determined as outlined by Gulluce et al. (2004). Add $0.5 \mathrm{~mL}$ of each sample to $1.0 \mathrm{~mL}$ of DPPH $(2 \mathrm{mM})$ ethanolic solution. The absorbance was read by spectrophotometer (Jasco V-530, Japan) at $517 \mathrm{~nm}$ against the blank after $30 \mathrm{~min}$ of the incubation period.

\section{Lipid peroxidation (TBA test)}

The level of lipid peroxidation in the berry samples was as outlined by Buege and Aust (1978), the amount of lipid peroxidation in the samples was determined as reactive metabolites 2-thiobarbituric acid (TBA) mainly malondialdehyde (MDA). The pink color absorbance was assessed at $532 \mathrm{~nm}$ and adjusted by subtracting the absorbance at $600 \mathrm{~nm}$ for non-specific turbidity by spectrophotometer (Jasco V-530, Japan). The concentration of MDA was calculated based on A532 A600 $\left(\Sigma=155 \mathrm{mM}^{-1} \mathrm{~cm}^{-1}\right)$. The outcome has been displayed as $\mu \mathrm{mol} / \mathrm{g}$ dry weight of the extract.

\footnotetext{
Reducing power

Reducing power was determined by Oyaizu (1986) technique. Each $0.5 \mathrm{~mL}$ sample was mixed with $0.2 \mathrm{M}$
}

sodium phosphate buffer $(2.5 \mathrm{~mL})$ and $1 \%$ potassium ferricyanide $(2.5 \mathrm{~mL})$ and incubated at $50{ }^{\circ} \mathrm{C}$ for $20 \mathrm{~min}$. Follwing the addition of $2.5 \mathrm{~mL}$ of $10 \%$ trichloroacetic acid, the mixture was centrifuged for $10 \mathrm{~min}$ at $200 \mathrm{~g}$. The upper layer $(5.0 \mathrm{~mL})$ was blended with $5.0 \mathrm{~mL}$ of deionized water and the test sample was read against the blank at $700 \mathrm{~nm}$.

\section{Metal chelating}

Metal chelating activity was consequently evaluated by $0.1 \mathrm{mM} \mathrm{FeSO}_{4}(0.2 \mathrm{~mL})$ and $0.25 \mathrm{mM}$ ferrozine $(0.4 \mathrm{~mL})$ in $0.2 \mathrm{~mL}$ of samples (Chew et al., 2009). After $10 \mathrm{~min}$ of incubating at room temperature, absorbance of the blend was recorded against a blank at $562 \mathrm{~nm}$ by spectrophotometer (Jasco V-530, Japan). The lower absorption of the test sample indicated greater chelating capacity of ferrous ion. The control contained all the reagents except test sample.

\section{Identification of bioactive compound by GC-MS}

Berry fruits extracts was engaged for GC-MS analysis using a HP G1800A instrument. Operating with a capillary column HP-5 (length $30 \mathrm{~m}$, i.d. $0.25 \mathrm{~mm}$ ); carrier gas: helium; flow rate: $1 \mathrm{~mL} \cdot \mathrm{min}^{-1}$; inlet temperature: $250{ }^{\circ} \mathrm{C}$; detector temperature $280{ }^{\circ} \mathrm{C}$; programmed temperature $100{ }^{\circ} \mathrm{C}$ for $3 \mathrm{~min}$, then $10-250{ }^{\circ} \mathrm{C}$, and $30-280{ }^{\circ} \mathrm{C}$ with a mass detector. Peak identification was carried out by comparing the retention times and mass spectra of eluting constituents with those of the Wiley library (Wiley7, NIST 0.1; Wiley, West Sussex, UK). In Agricultural Research Center, Giza, Egypt the GC-MS analysis was conducted.

\section{Statistical analysis}

The information was shown as the average $\pm S D$. All the statistical analyzes were carried out using an ANOVA and we used the multiple range tests of Duncan (Duncan, 1955) to compare the results of the experiments $(p \leq 0.05)$.

\section{RESULTS AND DISCUSSION}

\section{Yield extracts percentage of berry fruits}

Data in Figure 2 shows that the highest extract yield was $7.80 \%$ of red currant berry followed by blue berry $7.63 \%$ while strawberry gave the lowest yield 5.36\%. Whereas, black berry gave $7.20 \%$ and Egyptian black mulberry $6.36 \%$ (Aly et al., 2019).

\section{Phenolic and flavonoids contents of berry fruits}

Phenolic compounds are a big class of phytochemicals that exist as secondary metabolites present in crops. Most of them are phenolic acids, flavonoids, and tannins in human food. Besides contribution to sensory properties of food. Phenolic compounds also have a broad variety of biological and physiological tasks, similar to antiallergenic, anti-inflammatory, antimicrobial and antioxidant operations that benefit human health (Balasundram et al., 2006).

The findings showed that blue berry has the largest value of phenolic content $\left(6.74 \mathrm{mg} \cdot \mathrm{g}^{-1} \mathrm{DW}\right.$ of extract) followed by black berry (5.98 mg. $\mathrm{g}^{-1} \mathrm{DW}$ of extract), but the lowest content (1.62 mg.g ${ }^{-1} \mathrm{DW}$ of extract) was obtained from long mulberry (Figure 3 ). 


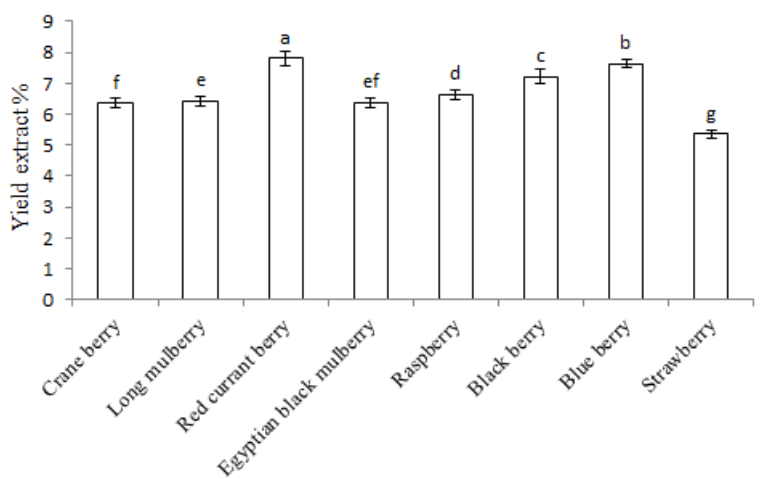

Figure 2 Yield extracts percentage of some different types of ripe berry fruits.
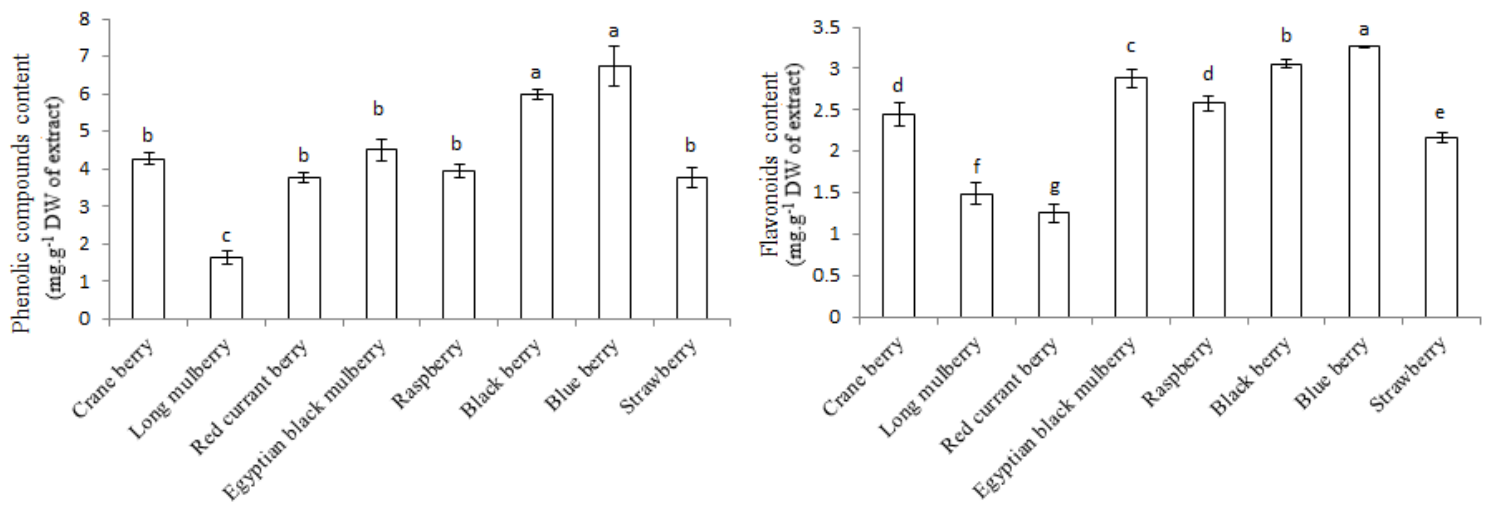

Figure 3 Phenolic compounds and flavonoid contents (mg. $\mathrm{g}^{-1} \mathrm{DW}$ of extract) in some different types of ripe berry fruits.

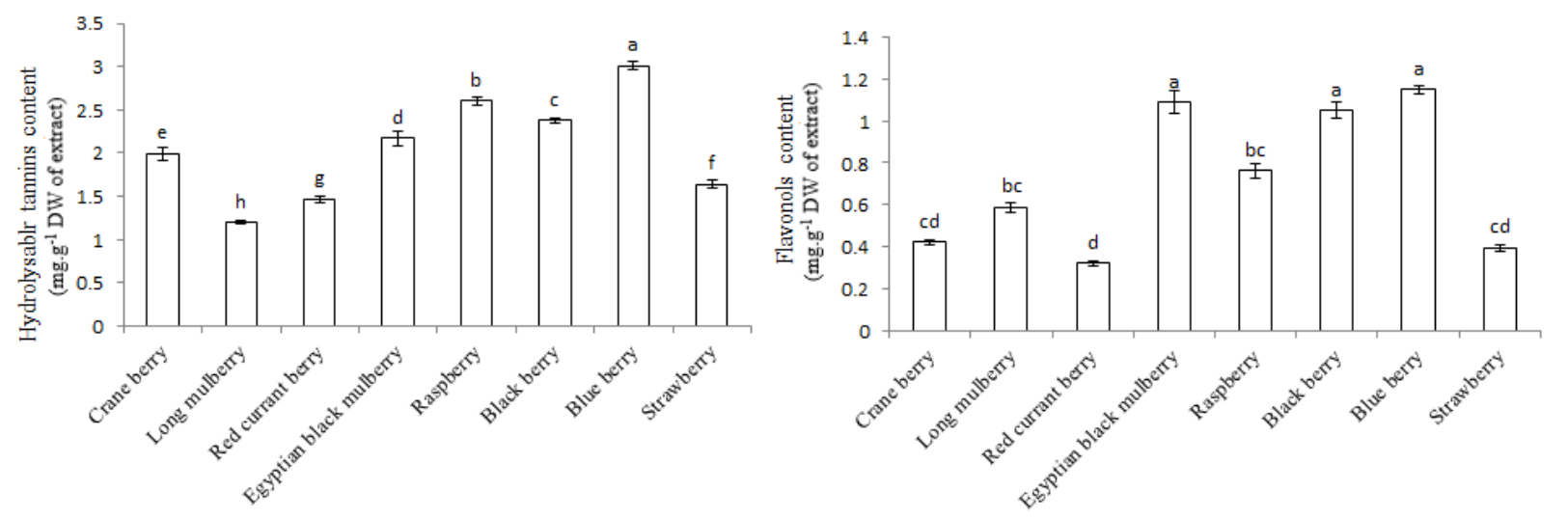

Figure 4 Hydrolysable tannins and flavonols content (mg. $\mathrm{g}^{-1} \mathrm{DW}$ of extract) in some different types of ripe berry fruits.

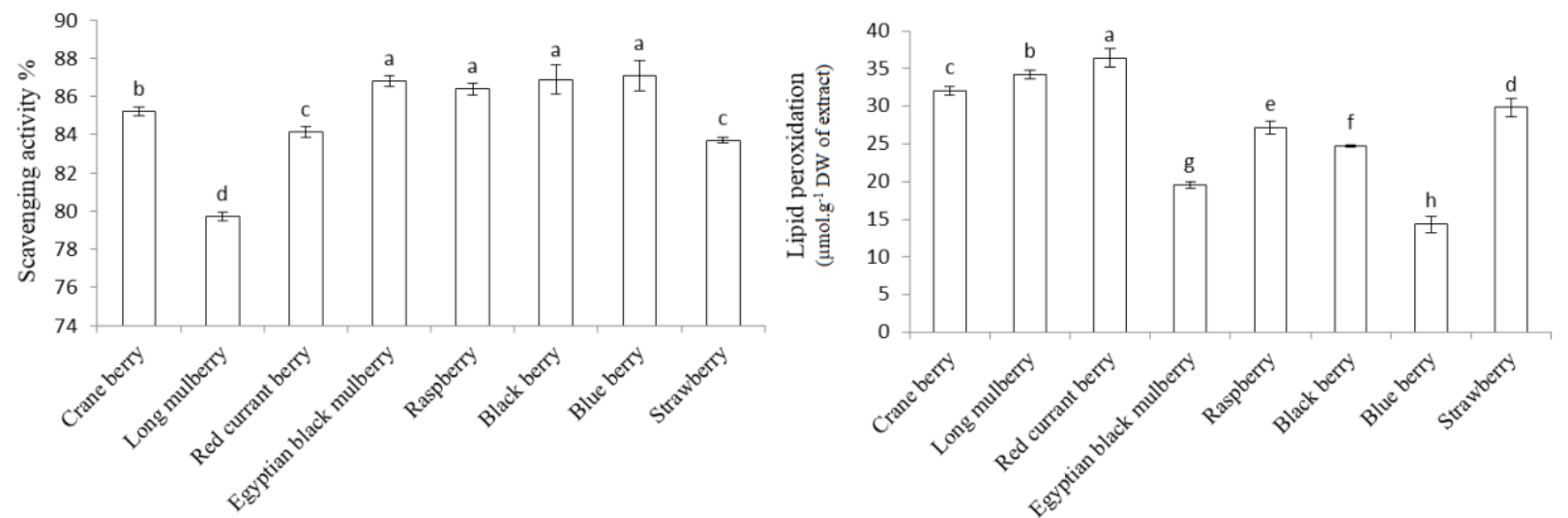

Figure 5 Scavenging activity percentage and lipid peroxydation ( $\mu \mathrm{mol} . \mathrm{g}^{-1} \mathrm{DW}$ of extract) in some different types of ripe berry fruits. 

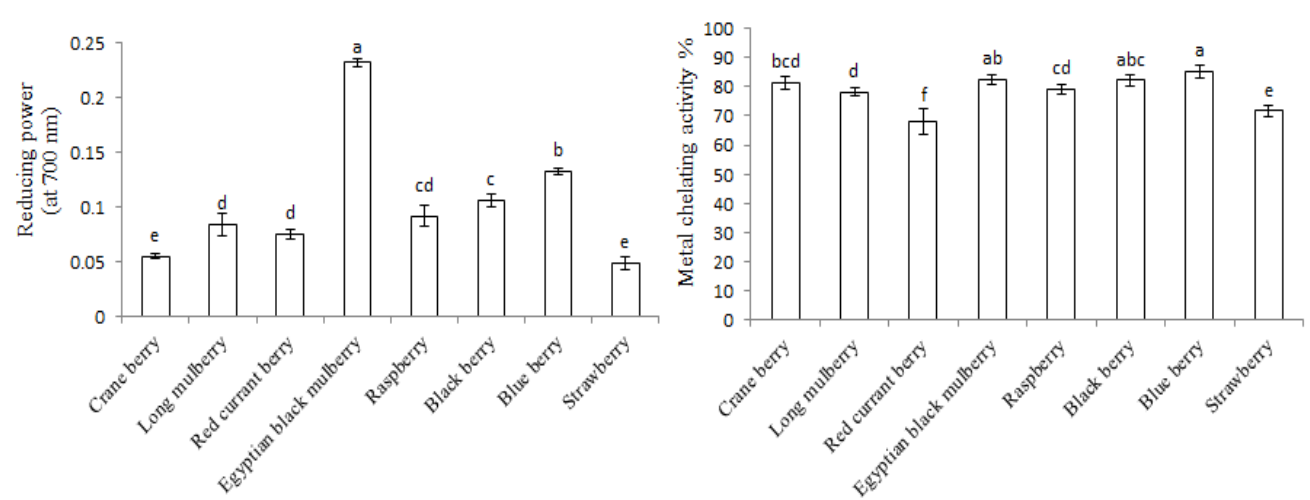

Figure 6 Reducing power and metal chelating activity percentage in some different types of ripe berry fruits.

For flavonoids, blue berry contains the highest content (3.26 mg. $\mathrm{g}^{-1} \mathrm{DW}$ of extract) followed by black berry (3.05 mg.g ${ }^{-1}$ DW of extract), while red currant berry gave the lowest content of flavonoids $\left(1.14 \mathrm{mg} \cdot \mathrm{g}^{-1} \mathrm{DW}\right.$ of extract) (Figure 3).

These findings are consistent with Huang et al. (2012) who studied the total phenolic content, and total flavonoid content of methanolic extracts of three berry fruits (blue berry, black berry and strawberry) growing in Nanjing and found that total phenolic content was 9.44, 5.58 and 2.72 mg gallic acid.g ${ }^{-1}$ DW of blue berry, black berry and strawberry, respectively. Also, indicated that blue berry and black berry contain the highest content of flavonoids and strawberry contains the lowest content. The phenolic compounds content for analyzed berries ranged from 1.62 to $6.74 \%$, these results are comparable to Diaconeasa et al. (2015) who indicated that the total phenolic compounds in some berries grown in Romania ranged from 200.3 to $678 \mathrm{mg}$ GAE.100g ${ }^{-1}$ FW. Likewise, Giovanelli and Buratti (2009) found that the total phenolic compounds values between 251 - $310 \mathrm{mg}$ GAE. $100 \mathrm{~g}^{-1} \mathrm{FW}$ for some cultivated blue berries and between 577 and $614 \mathrm{mg}$ GAE. $100 \mathrm{~g}^{-1} \mathrm{FW}$ for wild Italian blue berries. However, higher contents in other blackberries cultivars have been observed and reported by Deighton et al. (2000). The difference between the analyzed berries and others studies is due to differences in extraction method, environmental growth conditions, degree of maturity at harvest and genetic variations (Zadernowski et al., 2005). As antioxidants, antimutagenic, anticarcinogenic and their capacity to alter gene expression, phenolic compounds are of excellent significance (Marinova et al., 2005). Flavonoids are a big class of phenolic compounds discovered either free or as glycosides in various areas of the crop. It has many biological functions such as antimicrobial, antioxidant, anticancer, inhibition of protein kinase, etc (Bhat et al., 2005).

\section{Hydrolysable tannins and flavonols content of berry fruits}

Tannins are secondary metabolites that are widely distributed throughout the plant world and distinguished by their water solubility. The results in Figure 4 showed that blue berry and raspberry gave the highest content of

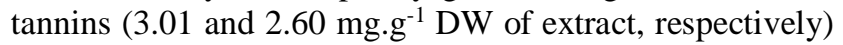
while the lowest value was from long mulberry
(1.20 mg.g ${ }^{-1}$ DW of extract). The results indicated that blue berry has the highest value of tannins. This result in agreement with Diaconeasa et al. (2015) who evaluated and compared some phytochemical compounds (phenolic compounds and tannins) in common fruits consumed in Romania (blueberry, blackberry, raspberry and cranberry) and found that the blue berry and raspberry contained the highest content of tannins.Concerning the content of flavonols, blue berry, black berry and Egyptian black mulberry gave the highest content of flavonols (1.15, 1.05 and $1.09 \mathrm{mg} . \mathrm{g}^{-1} \mathrm{DW}$ of extract, respectively) followed by raspberry $\left(0.762 \mathrm{mg} \cdot \mathrm{g}^{-1} \mathrm{DW}\right.$ of extract), while red currant berry gave lowest value of flavonols content $\left(0.321 \mathrm{mg} . \mathrm{g}^{-1}\right.$ DW of extract, respectively) (Figure 4).

\section{Antioxidant activity}

Antioxidant can be widely described as any drug that retards or inhibits a target molecule's oxidative harm (Yamagishi and Matsui, 2011) and prevent biological molecules such as proteins, lipids, and other molecules from oxidation by reactive oxygen species (ROS) such as hydroxyl radical $\left(\mathrm{OH}^{*}\right)$, hydrogen peroxide $\left(\mathrm{H}_{2} \mathrm{O}_{2}\right)$, superoxide $\left(\mathrm{O}_{2}{ }^{--}\right)$, etc. (Brindza et al., 2019). These reactive oxygen species are produced in the body either as a by-product of normal cellular aerobic respiration or exposure to environmental factors such as herbicides, radiation, pollution, and cigarette smoke (Alam et al., 2019). Also, antioxidant's primary characteristic its capacity to intercept free radical. Antioxidant compounds such as phenolic acids, polyphenols and flavonoids scavenge free radicals and prevent the oxidative harm resulting in many illnesses (Wu et al., 2011). A great cause of antioxidants is vegetables and fruits. Results from this research showed that blue berry, black berry and Egyptian black mulberry yielded elevated antioxidant activity scores accompanied by raspberry (Figures 5 and Figure 6). Concerning scavenging activity the blue berry gave $87.1 \%$ of scavenging activity followed by black berry and Egyptian black mulberry (86.88 and $86.81 \%$ respectively). Additionally, they gave a high content of metal chelating activity but red currant berry was on the contrary, giving lower value of metal chelating activity $(67.86 \%)$. There were slight differences in reducing power between berry fruits where Egyptian black mulberry gave the highest value in reducing power (0.232), but strawberry gave the lowest value of reducing power (0.049). 
Table 1 Bioactive compounds in different types of some ripe berry fruits.

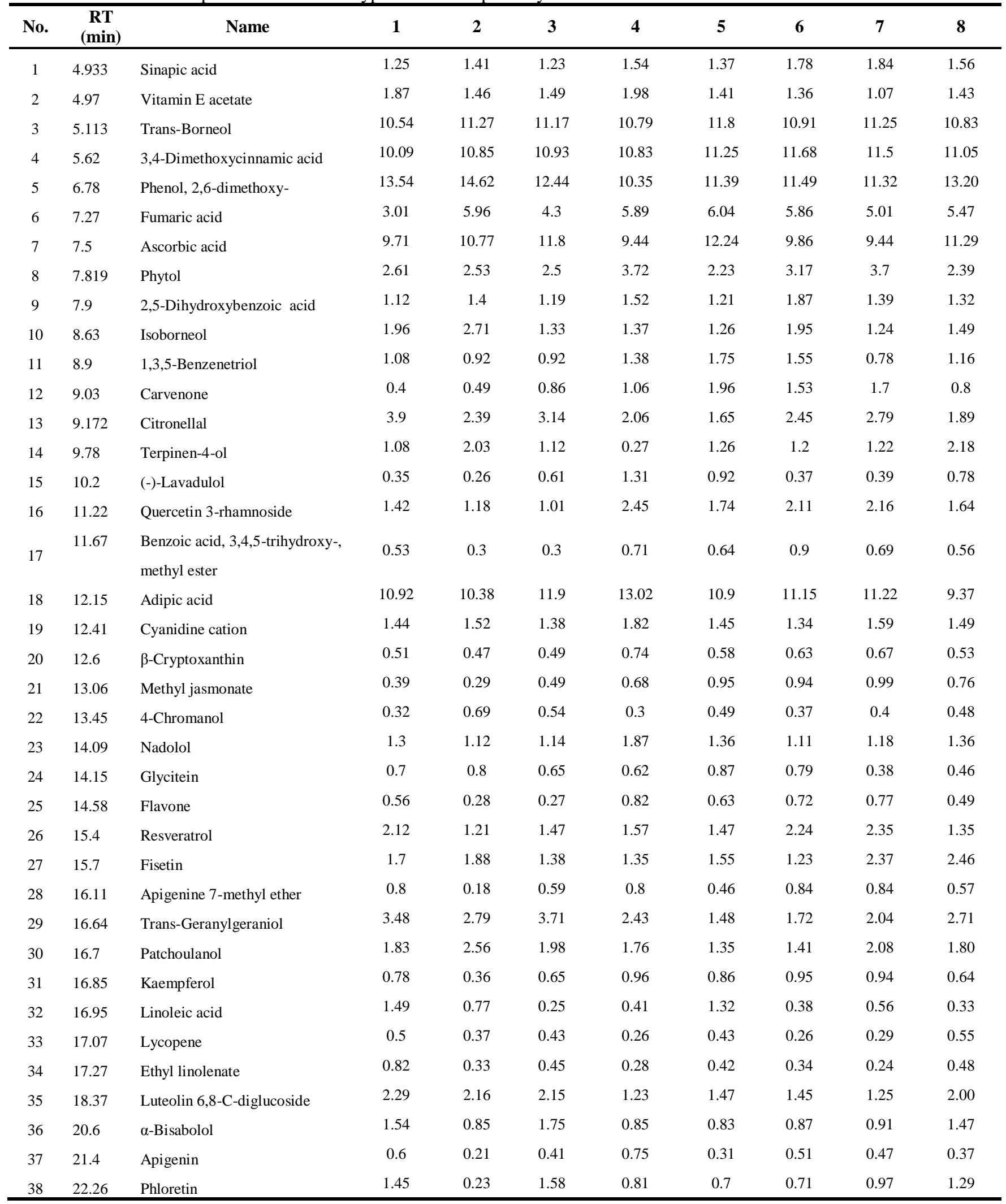

Note: 1: crane berry, 2: long mulberry, 3: red currant berry, 4: Egyptian black mulberry, 5: raspberry, 6: black berry, 7: blue berry and 8: strawberry.

This outcome is in agreement with Diaconeasa et al. (2015) who specified the greatest total phenolic compounds (678 mg.100g ${ }^{-1} \mathrm{FW}$ and $422 \mathrm{mg} 100 \mathrm{~g}^{-1} \mathrm{FW}$ respectively) also, blue berry and black berry had the greatest antioxidant activity. Also, Huang et al. (2012) indicated that the three berry fruits (blue berry, black berry and strawberry) grown in Nanjing manifest excellent antioxidant activity, the blue berry was the superior than black berry and strawberry. Burdulis et al. (2009) revealed that the blue berry cultivar (Berkeley) was the strongest antioxidant activity, and its scavenging activity was $82.13 \pm 0.51 \%$. While scavenging activity in bilberry 
specimens was $63.72 \pm 1.11 \%$. Blue berry cultivar (Covillei) reported the smallest antioxidant content (51.30 \pm 0.72 percent). The fruits of blue berry and bilberry are wealthy in flavonoids (quercetin, kempferol, epikatechin, catechin, and myrcetin), phenolic acids, chlorogenic acid and ascorbic acid, that are antiradical characteristics (Sellappan et al., 2002).

Anthocyanins and other polyphenolic compounds, the main contributors to the antioxidant activity in berries. Furthermore Vuong et al. (2018) discovered that blue berry ash fruit includes elevated content of phenolic compounds, flavonoids and proanthocyanidins that add to the antioxidant capacity of this fruit.

\section{Identification of bioactive compound by GC-MS}

The chemical composition of the berries varies according to cultivar, variety, location of growth, environmental conditions and harvest time, as well as postharvest treatments, so it is variable.

Gas chromatography-mass spectrometry (GC-MS) is an analytical technique that incorporates gas chromatography with mass spectrometry to recognize different substances in a test specimen.

\section{Identification of components}

Mass spectrometer was used to recognize the composition and the nature at distinct time periods. The heights of the distinct peaks show the comparative quantity in the different components current in the specimen. The compound's finger prints that can be recognized from the database of the library.

\section{GC-MS analysis}

Approximately 38 compounds were identified by GC-MS analysis in fruit extracts from berries. Table 1 presented the name of compounds with retention time (RT) and concentration (percent).

The prevailing compounds were Sinapic acid, Vitamin E acetate, Trans-Borneol, 3,4-Dimethoxycinnamic acid, Phenol, 2,6-dimethoxy-, Fumaric acid, Ascorbic acid, Phytol, 2,5-Dihydroxybenzoic acid, Isoborneol, 1,3,5Benzenetriol, Carvenone, Citronellal, Terpinen-4-ol, (-)Lavadulol, Quercetin 3-rhamnoside, Benzoic acid 3,4,5trihydroxy- methyl ester, Adipic acid, Cyanidine cation, $\beta$ Cryptoxanthin, Methyl jasmonate, 4-Chromanol, Nadolol, Glycitein, Flavone, Resveratrol, Fisetin, Apigenine 7methyl ether, Trans-Geranylgeraniol, Patchoulanol, Kaempferol, Linoleic acid, Lycopene, Ethyl linolenate, Luteolin 6,8-C-diglucoside, $\alpha$-Bisabolol, Apigenin and Phloretin. The investigation concluded that there are a number of active constituents responsible for many biological activities in the ethanolic extract of berry fruit, so these can be used to help protect against many diseases like cardiovascular disease, cancer and diabetes (van Breda, Briedé and de Kok, 2019). These active ingredients found in fruit extracts from berries include the following compounds: Sinapic acid has antioxidant (Zou et al., 2002), anti-inflammatory (Yun et al., 2008), anticancer (Hudson et al., 2000), antimutagenic, antiglycemic, and antimicrobial activities (Engels et al., 2012). Vitamin $E$ acetate is used in dermatological products such as skin creams and provides protection against the sun's ultraviolet rays. Ascorbic acid performs a significant part in a variety of body tasks inclusive collagen manufacturing and may decrease the danger of certain diseases due to its antioxidant action. Phytol has antioxidant, antiallergic (Santos et al., 2013), antinociceptive, antibacterial and anti-inflammatory activities (Ryu et al., 2011). Also, it is an excellent stimulant for immunity (Lim et al., 2006). 2,5Dihydroxybenzoic acid is used as antioxidant in some pharmaceutical preparations. Isoborneol has antiviral properties. Citronellal has antifungal properties and is used in aromatherapy. Terpinen-4-ol has an antibacterial and antifungal effect. (-)-Lavadulol is an important compound in the cosmetics industry. Quercetin 3-rhamnoside has an anti-inflammation effect used to treat cardiovascular disease. Cyanidine has a role as a metabolite, a neuroprotective agent and an antioxidant. $\beta$ Cryptoxanthin acts as a chemopreventive agent against lung cancer. Methyl jasmonate is used in plant defense and various developmental pathways such as seed germination, root growth, flowering, fruit ripening, and senescence. Flavone is a metabolite and a nematicide. Resveratrol acts as an antioxidant to prevent cancer and heart disease in the body. Fisetin has an anticancer activity that inhibits the activity of many pro-inflammatory cytokines and free radicals of scavenges. It also regulates the synthesis of glutathione, an internal antioxidant, anti-hyperlipidemic and anti-inflammatory agent, thereby reducing the effect of age and disease on the central nervous system function (Maher, 2015). Kaempferol acts as an antioxidant by decreasing oxidative stress and reducing the risk of various cancers (Chen and Chen, 2013). Linoleic acid is used in prostaglandins and cell membranes biosynthesis. Lycopene is an antioxidant (protective substance from cell damage). Luteolin 6,8-C-diglucoside has anti-inflammatory properties. $\alpha$-Bisabolol has anti-irritant, anti-inflammatory and antimicrobial properties. Apigenin has anti-tumor activity (Sung et al., 2016).

\section{CONCLUSION}

Berry fruits contain large quantities of phytochemical compounds (phenolic compounds, flavonoids and tannins) that act as antioxidants. There have been variations in the amount of these compounds between analyzed berries, as blue berry, black berry and Egyptian black mulberry have a high content of most bioactive compounds (phenolic compounds, flavonoids and tannins), while long mulberry and red currant berry have the lowest content for most of these compounds. The results of this study showed that blue berry, black berry and Egyptian black mulberry yielded elevated antioxidant activity scores accompanied by raspberry. Concerning scavenging activity the blue berry gave the highest value of scavenging activity followed by black berry and Egyptian black mulberry. Additionally, they gave a high content of metal chelating activity but red currant berry was on the contrary, giving lower value of metal chelating activity. There were slight differences in reducing power between berry fruits where Egyptian black mulberry gave the highest value in reducing power, but strawberry gave the lowest value of reducing power.Also, fruit extracts from berries contain an amount of effective components accountable for many biological operations. Thus, many diseases such as 
cardiovascular disease, cancer and diabetes can be treated with these components. This study therefore, reveals that berries are very nutritionally useful in protecting the body against many diseases.

\section{REFERENCES}

Alam, M. K., Rana, Z. H., Islam, S. N., Akhtaruzzaman, M. 2019. Total phenolic content and antioxidant activity of methanolic extract of selected wild leafy vegetables grown in Bangladesh: A cheapest source of antioxidants. Potravinarstvo Slovak Journal of Food Sciences, vol. 13, no. 1, p. 287-293. https://doi.org/10.5219/1107

Aly, A. A., Ali, H. G. M., Eliwa, N. E. R. 2019. Phytochemical screening, anthocyanins and antimicrobial activities in some berries fruits. J. Food Measurement and Characterization, vol. 13, no. 2, p. 911-920. https://doi.org/10.1007/s11694-018-0005-0

Andreasen, M., Landbo, A. K., Christensen, L., Hansen, A., Meyer, A. 2001. Antioxidant effects of phenolic rye (Secale cereale L.) extracts, monomeric hydroxycinnamates, and ferulic acid dehydrodimers on human low-density lipoproteins. J. Agricultural and Food Chemistry, vol. 49, no. 8, p. 4090-4096. https://doi.org/10.1021/jf0101758

Anttonen, M. J., Karjalainen, R. O. 2005. Environmental and genetic variation of phenolic compounds in red raspberry. J. Food Comp. Anal., vol. 18, p. 759-769. https://doi.org/10.1016/j.jfca.2004.11.003

Balasundram, N., Sundram, K., Samman, S. 2006. Phenolic compounds in plants and agri-industrial by-products: Antioxidant activity, occurrence, and potential uses. Food Chem., vol. 99, no. 1, p. 191-203. https://doi.org/10.1016/j.foodchem.2005.07.042.

Beekwilder, J., Hall, R. D., Ric de Vos, C. H. 2005. Identification and dietary relevance of antioxidants from raspberry. Biofactors, vol. 23, p. 197-205. https://doi.org/10.1002/biof.5520230404

Bhat, S. V., Nagasampagi, B. A., Sivakumar, M. 2005. Chemistry of natural products. ChemBioChem, vol. 6 no. 6, p. 1127-1128. https://doi.org/10.1002/cbic.200500134

Bobinaitè, R., Viškelis, P., Venskutonis, P. R. 2012. Variation of total phenolics, anthocyanins, ellagic acid and radical scavenging capacity in various raspberry (Rubus spp.) cultivars. Food Chemistry, vol. 132, no. 3, p. 1495-1501. https://doi.org/10.1016/j.foodchem.2011.11.137

Brindza, J., Grygorieva, O., Klymenko, S., Vergun, O., Mareček, J., Ivanišová, E. 2019. Variation of fruits morphometric parameters and bioactive compounds of Asimina triloba (L.) dunal germplasm collection. Potravinarstvo Slovak Journal of Food Sciences, vol. 13, no. 1, p. 1-7. https://doi.org/10.5219/1019

Buege, J. A., Aust, S. D. 1978. Microsomal lipid peroxidation. Methods in Enzymol., vol. 52, p. 302-310. https://doi.org/10.1016/S0076-6879(78)52032-6

Burdulis, D., Sarkinas, A., Jasutiene, I., Stackeviciene, E., Nikolajevas, L., Janulis, V. 2009. Comparative study of anthocyanin composition, antimicrobial and antioxidant activity in bilberry (Vaccinium myrtillus L.) and blueberry (Vaccinium corymbosum L.) Fruits. Acta Poloniae Pharmaceutica, vol. 66, no. 4, p. 399-408.

Deighton, N., Brennan, R., Finn, C., Davies, H. V. 2000. Antioxidant properties of domesticated and wild Rubus species. J. Sci. Food Agric., vol. 80, p. 1307-1313. https://doi.org/10.1002/1097-0010(200007)80:9<1307::AIDJSFA638>3.0.CO;2-P

Diaconeasa, Z., Ranga, F., Rugina, D., Leopold, L., Pop, O., Vodnar, D., Cuibus, L., Socaciu, C. 2015. Pheolic content and their antioxidant activity in various berries cultivated in Romania. Bulletin UASVM Food Science and Technology, vol. 72, no. 1, p. 99-103. https://doi.org/10.15835/buasvmcnfst: 11127

Duncan, D. B. 1955. Multiple range and multiple 'F' tests. Biometrics, vol. 11, no. 1, p. 1-42. https://doi.org/10.2307/3001478

Engels, C., Schieber, A., Ganzle, M. G. 2012. Sinapic acid derivatives in defatted oriental mustard (Brassica juncea L.) seed meal extracts using UHPLC-DAD-ESI-MSn and identification of compounds with antibacterial activity. Eur. Food. Res. Technol., vol. 234, no. 3, p. 535-542. https://doi.org/10.1007/s00217-012-1669-z

Giovanelli, G., Buratti, S. 2009. Comparison of polyphenolic composition and antioxidant activity of wild Italian blueberries and some cultivated varieties. Food Chem., vol. 112, no. 4, p. 903-908. https://doi.org/10.1016/j.foodchem.2008.06.066

Govindaraghavan, S. 2014. Pharmacopeial HPLC identification methods are not sufficient to detect adulterations in commercial bilberry (Vaccinium myrtillus) extracts. Anthocyanin profile provides additional clues. $\begin{array}{llll}\text { Fitoterapia, } & \text { vol. } & 99, & \text { p. }\end{array}$ https://doi.org/10.1016/j.fitote.2014.09.007

Gulluce, M., Sokmen, M., Sahin, F., Sokmen, A., Adiguzel, A., Ozer, H. 2004. Biological activities of the essential oil and methanolic extract of Micromeria fruticosa (L) Druce ssp serpy llifolia (Bieb) $\mathrm{PH}$ davis plants from the Eastern Anatolia region of Turkey. J. Sci. Food Agric., vol. 84, no. 7, p. 735-741. https://doi.org/10.1002/jsfa.1728

Huang, W., Zhang, H., Liu, W., Li, C. 2012. Survey of antioxidant capacity and phenolic composition of blueberry, blackberry, and strawberry in Nanjing. J. Zhejiang Univ. Sci. $B$ vol. 13, no. 2, p. 94-102. https://doi.org/ 10.1631/jzus.B1100137

Hudson, E. A., Dinh, P. A., Kokubun, T., Simmonds, M. S. J., Gescher, A. 2000. Characterization of potentially chemopreventive phenols in extracts of brown rice that inhibit the growth of human breast and colon cancer cells. Cancer Epidemiol Biomarkers Prev., vol. 9, no. 11, p. 1163-1170.

Chen, A. Y., Chen, Y. C. 2013. A review of the dietary flavonoid, kaempferol on human health and cancer chemoprevention. Food Chem., vol. 138, no. 4, 2099-2107. https://doi.org/10.1016/j.foodchem.2012.11.139

Chew, Y. L., Goh, J. K., Lim, Y. Y. 2009. Assessment of in vitro antioxidant capacity and polyphenolic composition of selected medicinal herbs from Leguminosae family in Peninsular Malaysia. Food Chem., vol. 116, no. 1, p. 13-18. https://doi.org/10.1016/j.foodchem.2009.01.091

Lachowicz, S., Kolniak-Ostek, J., Oszmianski, J., Wisniewski, R. 2017. Comparison of phenolic content and antioxidant capacity of bear garlic (Allium ursinum L.) in different maturity stages. J. Food Processing and Preservation, vol. 41, no. 1, p. 110. https://doi.org/10.1111/jfpp.12921

Lim, S. Y., Meyer, M., Kjonaas, R. A., Ghosh, S. K. (2006). Phytol-based novel adjuvants in vaccine formulation: 1 . assessment of safety and efficacy during stimulation of humoral and cell-mediated immune responses. J. Immune Based Ther. Vaccines, vol. 4, p. 6-8. https://doi.org/10.1186/1476-8518-4-6

Maher, P. 2015. Fisetin Acts on Multiple Pathways to Reduce the Impact of Age and Disease on CNS Function. Front Biosci., vol. 7, p. 58-82.

Marinova, D., Ribarova, F., Atanassova, M. 2005. Total phenolic and total flavonoids in Bulgarian fruits and 
vegetables. J.. Uni. Chem. Technol. Metal., vol. 40, no. 3, p. 255-260.

Nile, S. H., Park, S. W. 2014. Edible berries: Bioactive components and their effect on human health. Nutrition, vol. $30, \quad$ no. $2, \quad$ p. $134-144$. https://doi.org/10.1016/j.nut.2013.04.007

Oszmianski, J., Lachowicz, S. 2016. Effect of the production of dried fruits and juice from chokeberry (Aronia melanocarpa L.) on the content and antioxidative activity of bioactive compounds. Molecules, vol. 21, p. 1-14. https://doi.org/10.3390/molecules21081098

Oyaizu, M. 1986. Studies on products of browning reactions: Antioxidative activities of products of browning reaction prepared from glucosamine. Jap. J. Nut., vol. 44, p. 307-315. https://doi.org/10.5264/eiyogakuzashi.44.307

Price, M. L., Van Scoyoc, S., Butler, L. G. 1978. A critical evaluation of the vanillin reaction as an assay for tannin in sorghum grain. J. Agric. Food Chem., vol. 26, no. 5, p. 12141218. https://doi.org/10.1021/jf60219a031

Ryu, K. R., Choi, J. Y., Chung, S., Kim, D. H. 2011. Antiscratching behavioral effect of the essential oil and phytol isolated from Artemisia princeps Pamp in mice. Planta Med., vol. 77, no. 1, p. 22-26. https://doi.org/10.1055/s-0030$\underline{1250119}$

Santos, C. C., Salvadori, M. S., Mota, V. G., Costa, L. M., de Almeida, A. A., de Oliveira, G. A., Costa, J. P., de Sousa, D. P., de Freitas, R. M., de Almeida, R. N. 2013. Antinociceptive and antioxidant activities of phytol in vivo and in vitro models. Neuroscience J., vol. 2013, p. 1-9. https://doi.org/10.1155/2013/949452

Sellappan, S., Akoh, C. C., Krewer, G. 2002. Phenolic compounds and antioxidant capacity of Georgia-grown blueberries and blackberries. J. Agric. Food Chem., vol. 50, no 8, p. 2432-2438. https://doi.org/10.1021/jf011097r

Shahidi, F., Naczk, M. 1995. Methods of analysis and quantification of phenolic compounds. Food phenolic: sources, chemistry, effects and applications. Lancaster, England : Technomic Publishind Company, Inc, 287 p.

Skrovankova, S., Sumczynski, D., Mlcek, J., Jurikova, T., Sochor, J. 2015. Bioactive compounds and antioxidant activity in different types of berries. Int. J. Mol. Sci., vol. 16, no. $10, \quad$ p. 24673-24706. https://doi.org/10.3390/ijms161024673

Starast, M., Karp, K., Vool, E., Moor, U., Tonutare, T., Paal, T. 2007. Chemical composition and quality of cultivated and natural blueberry fruit in Estonia. Vegetable Crops Research Bulletin, vol. 66, no. 1, p. 143153. https://doi.org/10.2478/v10032-007-0016-6

Sung, B., Chung, H. Y., Kim, N. D. 2016. Role of apigenin in cancer prevention via the induction of apoptosis and autophagy. J. Cancer Prev., vol. 21, no. 4, p. 216-226. https://doi.org/10.15430/JCP.2016.21.4.216

van Breda, S. G. J., Briedé, J. J., de Kok, T. M. C. M. 2019. Improved preventive effects of combined bioactive compounds present in different blueberry varieties as compared to single phytochemicals. Nutrients, vol. 11, no. 1, p. 1-14. https://doi.org/10.3390/nu11010061

Vuong, Q. V., Pham, H. N. T., Vu, H. T., Dang, T. T., Ngo, T. V., Chalmers, A. C. 2018. Fruit characteristics, phytochemical and antioxidant properties of blueberry ash (Elaeocarpus reticulatus). Heliyon, vol. 4, no. 10, p. 1-16. https://doi.org/10.1016/j.heliyon.2018.e00834

Wu, Y. Y., Li, W., Xu, Y., Jin, E. H., Tu, Y. Y. 2011. Evaluation of the antioxidant effects of four main theaflavin derivatives through chemiluminescence and DNA damage analyses. J. Zhejiang Univ. Sci. B, vol. 12, no. 9, p. 744751. https://doi.org/10.1631/jzus.B1100041

Yamagishi, S., Matsui, T. 2011. Nitric oxide, a janus-faced therapeutic target for diabetic microangiopathy-Friend or foe? Pharmacol. Res., vol. 64, no. 3, p. 187194. https://doi.org/10.1016/j.phrs.2011.05.009

Yermakov, A. I., Arasimov, V. V., Yarosh, N. P. 1987. Methods of biochemical analysis of plants. Leningrad, Russia : Agropromizdat, p. 122-142 (in Russian).

Yun, K. J., Koh, D. J., Kim, S. H., Park, S. J., Ryu, J. H., Kim, D. G., Lee, J. Y., Lee, K. T. 2008. Anti-inflammatory effects of sinapic acid through the suppression of inducible nitric oxide synthase, cyclooxygase-2, and proinflammatory cytokines expressions via nuclear factor $-\kappa \mathrm{B}$ inactivation. $J$. Agric Food Chem., vol. 56, no. 21, p. 10265-10272. https://doi.org/10.1021/jf802095g

Zadernowski, R., Naczk, M., Nesterowicz, J. 2005. Phenolic acid profiles in some small berries. J. Agric. Food Chem., vol. 53, no. 6, p. 2118-2124. https://doi.org/10.1021/jf040411p

Zou, Y., Kim, A. R., Kim, J. E., Choi, J. S., Chung, H. Y. 2002. Peroxynitrite scavenging activity of sinapic acid (3,5dimethoxy-4-hydroxycinnamic acid) isolated from Brassica juncea. J. Agric Food Chem., vol. 50, no. 21, p. 5884-5890. https://doi.org/10.1021/jf020496z

\section{Acknowledgments:}

The authors would like to thank the Atomic Energy Authority for this research being supported and funded. They would like also, the editorial committee of the journal and the critics for their counteractive remarks and remarks that helped enhance this research.

\section{Contact address:}

Amina Aly, Natural Products Dept., National Center for Radiation Research and Technology, Atomic Energy Authority, P.O. 29, Nasr City, Cairo- Egypt, Tel.: + 20222749298,

E-mail: aly_amina@yahoo.co.uk

ORCID: https://orcid.org/0000-0003-0756-731X

*Rabab Maraei, Natural Products Dept., National Center for Radiation Research and Technology, Atomic Energy Authority, P.O. 29, Nasr City, Cairo- Egypt, Tel.: + 20222749298,

E-mail: alrahman 27israa@yahoo.com

ORCID: https://orcid.org/0000-0003-3295-8806

Omneya Abou El-Leel, Horticulture Research Institute, Agriculture Research Center, Giza- Egypt,

E-mail: om_night@ hotmail.com

ORCID: https://orcid.org/0000-0003-2998-0885

Corresponding author: * 